\title{
Energy Efficiency Measures and Convergence in China, Taking into Account the Effects of Environmental and Random Factors
}

\author{
Neng Shen', Jingjing Zhou', Wenjie Zou ${ }^{2 *}$ \\ ${ }^{1}$ School of Business, Soochow University, Suzhou 215021, Republic of China \\ ${ }^{2}$ School of Economics, Fujian Normal University, Fuzhou 350108, Republic of China
}

Received: 19 March 2014

Accepted: 3 August 2014

\begin{abstract}
This paper measures energy efficiency in China using the three-stage data envelopment analysis (DEA) model and then tests the convergence of China's energy efficiency. The study finds that environmental factors and random factors both have significant impacts on energy efficiency. After eliminating the influences of environmental and random error factors, the results present that the pure technical efficiency improves and the scale efficiency decreases, but pure technical efficiency is far lower than scale efficiency in terms of energy utilization, which indicates that low pure technical efficiency is the main factor constraining China's energy efficiency. China's energy efficiency presents obvious regional differences, and the energy efficiency in eastern regions is higher than that in midwestern regions. Based on the matching relationship between energy efficiency and input level, China can be regionally divided into four energy utilization modes: high efficiency and high input mode, high efficiency and low input mode, low efficiency and high input mode, and low efficiency and low input mode. Nationally, the difference in regional energy efficiency should maintain a relatively high level in the short term; divergence occurs in terms of pure technical efficiency and overall technical efficiency, while scale efficiency manifests a significant absolute convergence feature. Differential energy strategy should be carried out according to the features of different districts. Eastern regions should decrease the dependence on external energy, and develop advanced techniques with lower energy consumption. The improvement of energy efficiency in Midwest regions should depend on changing a traditionally highly energy-intensive industrial structure, undertaking clear industrial transfer from the east, excavating latent energy savings with the high-energy industry sector, and accelerating the transformation to an intensive pattern. Strengthening the energy corporation of China not only enhances energy efficiency in eastern regions but also improves energy efficiency in midwestern regions by spillover effect. Accordingly, it could improve energy efficiency balance and robustness.
\end{abstract}

Keywords: energy efficiency, three-stage DEA model, undesirable output, convergence

\section{Introduction}

While the emission reductions and schedules of various countries are not clearly defined under the framework prin-

*e-mail: fjgt263@163.com ciple of "common but differentiated responsibilities," China unilaterally announced at the Copenhagen World Climate Conference in 2009 that it would cut carbon intensity $40-50 \%$ by 2020 . Likewise, in order to achieve sustainable development, the Chinese government proposed the construction of a resource-conserving society. However, 
domestic energy demand is continuously rising, there is a distinct imbalance between supply and demand, regional energy efficiency is uneven, and environmental pollution is constantly growing. Studies show that $\mathrm{CO}_{2}$ generated by energy consumption in China accounts for $75 \%$ of China's total emissions. Relevant studies have noted that, although its per capita $\mathrm{CO}_{2}$ emissions still lag far behind that of developed countries, its total $\mathrm{CO}_{2}$ emissions will soon exceed the U.S. to rank first in the world. In the past two decades, China has taken active measures for environmental improvement, but a dire environmental situation remains, whereby the key to solving environmental pollution and achieving sustainable development lies in energy efficiency.

Energy efficiency refers to using less energy for the same amount of service or useful output [1]. In view of its importance, scholars have extensively studied the measurement of energy efficiency. One measure is the single-factor energy efficiency method, i.e., adopting the ratio of output to energy input to define energy efficiency [2]. While this index is simple, an economy's output is determined not just by energy input, but also by the input of factors such as capital, labor, etc. In addition, the single-factor energy efficiency index fails to consider the influence of various "non-efficiency"-related market factors on energy input. For example, the effect of substituting energy as a result of a change in the relative energy price may also render a change in energy efficiency.

A second measure is the total-factor energy efficiency method, i.e., taking the combined effect of various input factors into consideration. This method contains two submethods: the parametric method and non-parametric method. The non-parametric method of data envelopment analysis (DEA) can calculate the distance between a decision-making unit and the frontier and has thus become a powerful tool in the efficiency literature. The concept of total-factor energy efficiency is first introduced by $\mathrm{Hu}$ and Wang [3], who emphasize the relationship between economic output and multi-input, and take energy, labor, and capital storage as input factors to evaluate the energy efficiency of China from 1995 to 2002 with the traditional DEA model. The studies on the measurement of total energy efficiency with non-parameter method (DEA) mainly focus on two aspects: one mainly uses capital, labor, and energy as inputs and GDP as output, and measures totalfactor energy efficiency and productivity with traditional Malmquist productivity index [4-7]. While it fails to measure the efficiency under the circumstance of undesirable output (such as $\mathrm{CO}_{2}$ ). Another measure is total-factor energy efficiency by bringing pollutants into production model. It regards pollutants as inputs or undesirable outputs, and uses the Malmquist-Luenber (ML) productivity index and directional distance function introduced by Chung et al. [8] in measuring the productivity of Swedish pulp mills to measure total-factor energy efficiency. This method makes a comprehensive consideration of higher outputs and lower pollution [9-14].
At present, many scholars pay great attention to energy efficiency convergence problems. The relative research works are as follows: by measuring the energy efficiency of 7 European countries from 1999 to 2004, Noailly [15] makes a metrological analysis on energy efficiency promotion from the perspective of environmental policy on technological innovation. Streimikiene [16] uses the LMDI method to calculate the energy efficiency from 1995 to 2009 in Lithuania, and finds that energy efficiency is declining. Herrerias [17] uses the weighted dynamic distribution method to analyze the energy efficiency of 83 countries, the empirical results of which indicate that the energy efficiency of developing countries remain at a high level of convergence, while developed countries have at least two convergence clubs: the lowest level and a higher level of energy efficiency. Meng [18] makes empirical analysis of conditional convergence of energy efficiency of $25 \mathrm{UN}$ countries in 1960-2010, which is subjected to human capital factors. Stern [19] analyzes 85 countries energy efficiency over 37 years with the stochastic frontier production function method and finds that the energy efficiency of these 85 countries exists in convergence.

Nevertheless, these studies on energy efficiency in the existing literature fail to examine the influence of both external environmental factors and random error factors. As pointed out by Fried [20], low efficiency might be caused by imperfect internal management or by the external environment and random errors, meaning that the traditional non-parametric method is unable to uncover the influence of external environmental factors and random error factors on efficiency. As a result, the efficiency value obtained does not objectively reflect the management level of the decision-making unit.

The present paper discusses the following elements. First, the three-stage DEA model is used to regionally measure and deconstruct China's energy efficiency between 2000 and 2012 on the basis of controlling for external environmental factors. Second, with respect to the gap in the current literature in adopting a single pollution index, the entropy method is employed to integrate main pollution emissions into the composite index and adopt it as undesirable output. Third, the existence of convergence in China's regional energy efficiency without considering the influence of environmental factors is verified, providing a policy basis for the sustainable development of China's regional energy.

\section{Setting Up the Three-Stage DEA Model}

The first three-stage DEA model is put forward by Fried. The three-stage model can distinguish the real efficiency value of the DMUs which benefit from favorable conditions or measurement error. In addition, it also has the following advantages: identify input and output of nonradial slack variables; determine the adjustment of efficiency under the effects of environmental variables and statisti- 
cal noise; put DMUs under the same condition. The three steps of this method are as follows:

(1) Utilize the traditional DEA model to measure technical efficiency, while the efficiency calculated in this step includes external environmental and statistical noise factors

(2) Regard the input or output slacks as dependent variables, the external environment variables as independent variables to build SFA regression equation. In this step, input and output can be adjusted according to the results

(3) Use the adjusted input and output values for variables into the DEA model; the efficiency calculated in this step excludes external environmental and statistical noise factors and can reflect real energy efficiency.

The three-stage DEA model has been verified and applied in many other fields, and embodies its advantages in evaluation. Shang [21] evaluates the operation efficiency of Taiwan's hospitality industry with the three-stage DEA model. Jonchi and Terri [22] evaluate the operation efficiency of the banking sector in Taiwan. All the research conclusions validate that there is great difference between the three-stage DEA model and traditional DEA model in evaluation results; environmental factors and statistical error do impact efficiency.

First Stage:

\section{Traditional DEA Model}

DEA is one of the most common linear programming techniques and is based on non-parametric frontier efficiency analysis. Charms, Cooper, and Rhodes [23] first proposed the CCR model, marking DEA as a new study field. DEA is able to inspect energy production technology effectiveness and scale efficiency on a production frontier. This study utilizes two basic models, CCR and BBC, to measure technical efficiency (TE) and pure technical efficiency (PTE).

In the case of constant returns to scale, this study introduces dual variables $\lambda_{1}, \lambda_{2}, \ldots, \lambda_{n}, \theta$, and slack variable $s$ were introduced, and sets up the mathematical expression of the input-CCR model as follows:

$$
\begin{aligned}
& \min \theta \\
& \text { s.t }\left\{\begin{array}{l}
\sum_{j=1}^{n} \lambda_{j} x_{j}+s^{-}=\theta x_{0} \\
\sum_{j=1}^{n} \lambda_{j} y_{j}-s^{+}=y_{0} \\
s^{-} \geq 0, s^{+} \geq 0, \lambda_{j} \geq 0 \\
\text { Ounconstricted }
\end{array}\right.
\end{aligned}
$$

In formula (1), $\theta$ represents a decision-making unit's (DMU) technical efficiency (TE). For the case of variable returns to scale, the mathematical expression of the input$\mathrm{BCC}$ model is: $\min \eta$

$$
\text { s.t }\left\{\begin{array}{l}
\sum_{j=1}^{n} \lambda_{j} x_{j}+s^{-}=\eta x_{0} \\
\sum_{j=1}^{n} \lambda_{j} y_{j}-s^{+}=y_{0} \\
s^{-} \geq 0, s^{+} \geq 0, \lambda_{j} \geq 0 \\
\sum_{j=1}^{n} \lambda_{j}=1
\end{array}\right.
$$

In formula (2), $\eta$ represents each DMU's pure technical efficiency (PTE), and $x_{0}^{*}=\eta x_{0}-s^{-}$is the optimal input value under a given output level. It could be concluded that the above two basic models are able to obtain each DMU's scale efficiency $S E=T E / P T E$. As the DEA model does not discriminate between external environmental factors, random errors, and internal management factors' impact on production efficiency, the efficiency value does not reflect the real cause of inefficiency. Therefore, in order to objectively appraise a DMU's production efficiency, the exogenous factors should be peeled off such that the difference between $x_{0}$ and $x_{0}^{*}$ is the input margin that should be adjusted in the second phase.

\section{Second Stage: Similar SFA Model}

The major task of the second stage is to estimate the environmental variables' influence on the efficiency value and to analyze the input margin from the first stage so as to spin off management inefficiency, environmental inefficiency, and random factors. Fried considered that by constructing the Stochastic Frontier Analysis (SFA) model, each factor's impact on productivity could be respectively gauged, thus acquiring input redundancy caused merely by management inefficiency. In order to correspond with the input-based DEA model in the first stage, this study establishes the input-oriented SFA model to investigate the differences between $N$ input variables of $M$ decision-making unit. The difference expression is as follows:

$$
S_{i j}=x_{i j}-x_{i j}^{*} \geq 0 \quad(i=1, \ldots, M ; j=1, \ldots, N)
$$

In formula (3), $x_{i j}$ represents input item $j$ of $D M U_{i}$, and $x_{i j}^{*}$ is the optimal value of $x_{i j}$, denoting actual input value. Here, $S_{i j}$ is obtained from the first stage as a dependent variable and environmental factor $z_{i}$ is considered as an independent variable. The SFA regression function is constructed as:

$$
S_{i j}=f_{j}\left(z_{i} ; \beta\right)+v_{i j}+u_{i j} \quad(i=1, \ldots, M ; j=1, \ldots, N)
$$

In formula (4), $f_{j}\left(z_{i} ; \beta\right)$ is how the environmental variables affect input slacks $s_{i j}$, and usually $f_{j}\left(z_{i} ; \beta\right)=z_{i}^{\mathrm{T}} \beta$, where $\beta$ is the regression coefficient of environmental variables. 
Here, $z_{i}$ and $v_{i j}+u_{i j}$ are complicated random errors. This study hypothesizes that $v_{i j}: N\left(0, \sigma_{j v}^{2}\right)$ denotes random disturbances, $u_{i j}: N^{-}\left(\mu^{j}, \sigma_{j v}^{2}\right)$ denotes management inefficiency, and $v_{i j}$ is independent from $u_{i j}$. The hypothesis of random items should extract random disturbances from the complicated random errors while excluding exogenous factors. The conditional estimation of management inefficiency is:

$$
\hat{E}[u \mid v+u]=\hat{\mu}_{*}+\hat{\sigma}_{*} \frac{f\left(-\hat{\mu}_{*} / \hat{\sigma}_{*}\right)}{1-F\left(-\hat{\mu}_{*} / \hat{\sigma}_{*}\right)}
$$

In formula (5), $\hat{\mu}_{*}=-\hat{\sigma}_{u}^{2} \hat{\varepsilon} / \hat{\sigma}^{2}, \hat{\sigma}_{*}=-\hat{\sigma}_{u}^{2} \hat{\sigma}_{v}^{2} \hat{\varepsilon} / \hat{\sigma}^{2}$, and $\hat{\sigma}^{2}=\hat{\sigma}_{u}^{2}+\hat{\sigma}_{v}^{2}$. Here, $f$ and $F$ respectively denote the density function and the cumulative distribution function of standard normal distribution. The estimation of random disturbances is:

$$
\begin{gathered}
\hat{E}\left[v_{i j} \mid v_{i j}+u_{i j}\right]=S_{i j}-z_{j} \hat{\beta}-\hat{E}\left[u_{i j} \mid v_{i j}+u i_{j}\right] \\
i=1, \cdots, M ; j=1, \cdots, N
\end{gathered}
$$

After regression, this study is able to separately obtain environmental factors' impacts on technical efficiency $z \hat{\beta}$ and random disturbances' impacts $\hat{E}\left[v_{i j} \mid v_{i j}+u_{i j}\right]$. Thus, we can extract the exogenous factors' interference on the inputs, allowing the modified inputs to report production efficiency more objectively. In accordance with the most efficient DMU, we now revise other samples' inputs:

$$
\begin{gathered}
x_{i j}^{\prime}=x_{i j}+\max _{i}\left\{z_{i} \hat{\beta}\right\}-z_{i} \hat{\beta}+\left[\max _{i}\left\{\hat{v}_{i j}\right\}-\hat{v}_{i j}\right] \\
i=1, \cdots M ; j=1, \cdots, N
\end{gathered}
$$

In formula (7), $x_{i j}^{\prime}$ is adjusted inputs, $\max _{i}\left\{z_{i} \hat{\beta}\right\}-z_{i} \hat{\beta}$ aims to preclude environmental influences and places all DMUs under the same external environmental conditions, and $\max _{i}\left\{\hat{v}_{i j}\right\}-\hat{v}_{i j}$ targets to allow all DMUs to confront the same random disturbances. Hence, the final differences in production efficiency are attributed to internal management factors.

\section{Third Stage: \\ Revised DEA Model}

This stage re-evaluates DMUs whose inputs have been revised by two basic DEA models mentioned in the first stage. The result is that production efficiency has peeled off environmental factors and random factors.

\section{Variables and Data}

\section{Input and Output Indices}

With respect to the determination of the input and output of DEA, this study adopts three input indices (capital, labor, and energy) and two output indices (GDP and pollution emission).

\section{Capital Stocks}

Let capital stocks represent capital investment. As the data of capital stocks cannot be obtained directly, this paper employs the perpetual inventory method to estimate the capital stocks of various regions in China.

\section{Labor}

This variable is usually measured in terms of the effective labor time of employees, but due to a lack of effective statistical data, the current study adopts the total number of employees in various regions as a replacement.

Current total number of employees $=($ employment at the end of the year + employment at the end of the last year)/2.

\section{Energy}

Due to different energy consumption types in various regions, and for purposes of a uniform comparison, the consumption of the four types of primary energy (coal, petroleum, natural gas, water, and electricity) needs to be converted into a uniform unit. The data comes from energy balance table by region of the China Energy Statistical Year Book. The unit of measurement of energy input is "ton of standard coal equivalent."

\section{Desirable Output}

This refers to gross domestic product (GDP) as represented by the constant price of 1990 .

\section{Undesirable Output}

This refers to industrial wastewater, industrial waste gas, and waste. The data of industrial wastewater and waste can be obtained from China Statistical Yearbook, while the data of waste gas emissions of each province are not directly given. Total emissions of waste gas in this paper include the following sections: industrial sulfur dioxide, living sulfur dioxide, industrial smoke, living soot and industrial dust. The DEA method does not apply to the case of excessive input and output indices. Therefore, the present paper employs the improved entropy method to integrate various industrial emission indices into one pollution emission index. Considering the practical significance of the model, the reciprocal value of the pollution emission index is adopted as the undesirable output index.

\section{Environmental Variable Indices}

The factors selected as the environmental variables are those that influence energy efficiency, but cannot be subjectively controlled. The present paper selects the following factors as environmental variables.

\section{Government Intervention}

This is represented by the proportion of local fiscal expenditure in local GDP. 


\section{Industrial Structure}

This is represented by the proportion of local industrial output in total output and includes a consideration of the differences between various industrial sectors in energy consumption.

\section{Marketization Level}

This is represented by the ratio of local non-state-owned industrial output to total industrial output.

\section{Economic Openness}

This is represented by the ratio of the amount of foreign direct investment (FDI) to the total amount of capital stocks.

\section{Energy Factors \\ (Energy Price, Energy Endowment, and Energy Consumption Structure)}

The energy price is represented by the purchase price indices of raw materials, fuels, and energy; the energy endowment is represented by the ratio of total energy consumption to energy output; the energy consumption structure is represented by the proportion of raw coal consumption in energy consumption.

In view of data availability and integrity, this study selects 30 provinces (autonomous regions and municipalities directly under the control of the central government; hereinafter abbreviated to "province") in China between 2000 and 2012 as the sample (Tibet is excluded due to incomplete data). The data are respectively derived from China Statistical Yearbook, China Environment Yearbook, China Labour Statistical Yearbook, China Energy Statistical Yearbook, and other relevant yearbooks of various provinces.

\section{Empirical Calculation and Results}

\section{Empirical Results of Traditional DEA in the First Stage}

The first stage uses Deap 2.1 software to measure the mean energy efficiency level of 30 provinces in China between 2000 and 2012. As indicated by the results in Table 1 , without taking into account the influence of environmental variables and random error factors, the mean comprehensive technical efficiency is 0.842 , the mean pure technical efficiency is 0.899 , and the mean scale efficiency of China's energy efficiency is 0.937. Among the 30 provinces, four (Shanghai, Zhejiang, Fujian, and Henan) are at the frontier of technical efficiency, with the other provinces somewhat further away from optimal technical efficiency. The results also indicate that scale efficiency is higher than pure technical efficiency in most provinces, meaning that technical inefficiency in most provinces
Table 1. Energy efficiency estimation result in China (mean value between 2000-11)

\begin{tabular}{|c|c|c|c|}
\hline Region & $\mathrm{TE}$ & PTE & $\mathrm{SE}$ \\
\hline Beijing & 0.892 & 0.918 & 0.972 \\
\hline Tianjin & 0.884 & 0.913 & 0.968 \\
\hline Hebei & 0.858 & 0.876 & 0.979 \\
\hline Sanxi & 0.804 & 0.843 & 0.954 \\
\hline Inner Mongolia & 0.742 & 0.842 & 0.881 \\
\hline Liaoning & 0.922 & 0.949 & 0.972 \\
\hline Jilin & 0.816 & 0.863 & 0.945 \\
\hline Heilongjiang & 0.744 & 0.882 & 0.844 \\
\hline Shanghai & 1.000 & 1.000 & 1.000 \\
\hline Jiangsu & 0.906 & 0.925 & 0.979 \\
\hline Zhejiang & 1.000 & 1.000 & 1.000 \\
\hline Anhui & 0.770 & 0.801 & 0.962 \\
\hline Fujian & 1.000 & 1.000 & 1.000 \\
\hline Jiangxi & 0.785 & 0.832 & 0.943 \\
\hline Shandong & 0.841 & 0.924 & 0.910 \\
\hline Henan & 1.000 & 1.000 & 1.000 \\
\hline Hubei & 0.801 & 0.859 & 0.932 \\
\hline Hunan & 0.796 & 1.000 & 0.796 \\
\hline Guangdong & 0.913 & 0.961 & 0.950 \\
\hline Guangxi & 0.704 & 0.792 & 0.889 \\
\hline Hainan & 0.787 & 0.912 & 0.863 \\
\hline Chongqing & 0.794 & 0.847 & 0.938 \\
\hline Sichuan & 0.907 & 0.943 & 0.962 \\
\hline Guizhou & 0.794 & 0.831 & 0.955 \\
\hline Yunnan & 0.707 & 0.826 & 0.856 \\
\hline Shanxi & 0.734 & 0.822 & 0.893 \\
\hline Gansu & 0.813 & 0.926 & 0.878 \\
\hline Qinghai & 0.760 & 0.832 & 0.913 \\
\hline Ningxia & 1.000 & 1.000 & 1.000 \\
\hline Xinxiang & 0.774 & 0.845 & 0.916 \\
\hline Mean value & 0.842 & 0.899 & 0.937 \\
\hline
\end{tabular}

TE is technical efficiency, PTE is pure technical efficiency, $\mathrm{SE}$ is scale efficiency, $\mathrm{TE}=\mathrm{PTE} \times \mathrm{SE}$.

emerges from pure technical inefficiency rather than scale inefficiency. In addition, according to these first-stage results, pure technical inefficiency is the main factor restraining China's energy efficiency, but without considering the influence of external environmental factors and random error factors, there is the danger that the value of pure technical efficiency may be underestimated. Moreover, in this context, there also exists the possibility that the value 
Table 2. Estimation results of SFA.

\begin{tabular}{|l|c|c|c|}
\hline & Capital slack variables & Labor slack variables & Energy slack variables \\
\hline Constant item & 0.4543 & $0.9765^{*}$ & 0.4362 \\
\hline Government intervention & $0.1832^{* *}$ & $0.1087^{* * *}$ & $-0.0973^{* *}$ \\
\hline Industrial structure & $-0.6508^{* * *}$ & $-0.7654^{* * *}$ & $-0.6650^{* * *}$ \\
\hline Marketization level & $-0.3965^{* * *}$ & $0.5654^{* *}$ & $-0.0-0.0978978^{* *}$ \\
\hline Economic openness & $-0.2756^{* *}$ & $-0.1876^{* *}$ & $0.8676^{* *}$ \\
\hline Energy consumption & $0.6552^{* *}$ & $0.7098^{* *}$ & $0.3435^{* * *}$ \\
\hline Energy endowment & $0.4765^{* * *}$ & $0.3986^{* * *}$ & $-0.5756^{* * *}$ \\
\hline Energy price & $-0.4764^{* * *}$ & $-0.2976^{* * *}$ & $1465.0987^{*}$ \\
\hline$\sigma^{2}$ & $890.0987^{* *}$ & $786.2321^{* *}$ & 0.9287 \\
\hline$\Gamma$ & 0.9324 & 0.9464 & $-156.6776^{* *}$ \\
\hline Log-likelihood function & $-126.5676^{* *}$ & $-276.0965^{* *}$ & 32.6897 \\
\hline LR test of the one-sided error & 11.6762 & 15.3276 & \\
\hline
\end{tabular}

$*, * *$, and $* * *$ represent significance levels of $10 \%, 5 \%$, and $1 \%$, respectively.

of scale efficiency may be overestimated. In order to evaluate these in greater depth, further analysis is required.

\section{Results of SFA Regression Analysis in the Second Stage}

The second stage estimates the influence of environmental variables on energy efficiency. For this purpose, the slack variables of various input variables calculated in the first stage are taken as dependent variables, while government intervention, industrial structure, marketization level, economic openness, and energy factors are taken as independent variables. The aim is to analyze the extent to which external environmental variables significantly influence the difference between ideal and actual input variables. Frontier 4.1 software is employed for the SFA regression analysis with the results shown in Table 2 . Here it can be seen that all $\gamma$ values in the SFA analysis exceed 0.9 , and that the LR test is significant at the level of $1 \%$, which proves that the application of the SFA analysis is appropriate. The implications of these results indicate that those environmental variables in the present paper do exert an influence over energy efficiency. This then makes it necessary to adjust the original input and to analytically confront all the provinces with the same external environmental features in order to obtain accurate results at the third stage.

This study further investigates the coefficients of environmental variables to the three types of input slack variables. Since environmental variables are regressive for various input slack variables, a negative regression coefficient means that an increase in environmental variables is conducive to input slack variable reduction - that is, it is conducive to a reduction in waste of various input variables or an output increase. Conversely, a positive regression coefficient means that increasing environmental variables raises input slack variables, thereby rendering the waste of var- ious input variables or an output reduction. According to the regression coefficients of environmental factors to input slack variables, the following conclusions may be drawn with reference to these factors.

1. Government intervention. The coefficients of the capital, labor, and energy consumption slack variables are all significantly positive at $0.1832,0.1087$, and 0.0973 , respectively, suggesting that economic intervention by the government counts against a reduction in various input slack variables. Arguably, the reason is that excessive intervention by the government negatively influences the rational allocation of various production resources by the market under a market economic system.

2. Industrial structure. The coefficients of the capital, labor, and energy consumption slack variables are all significantly negative at $-0.6508,-0.7654$, and -0.7870 , respectively, suggesting that an increase in the proportion of gross industrial output value reduces the waste of various inputs. This is consistent with the viewpoints of Shi Fu and Shen Kunrong [24], who noted an inverted U-type relationship between industrial output proportion and energy efficiency in the long run. In this context, with the upgrading of industrial structure, energy factors will transfer from sectors of low productivity growth to sectors of high productivity growth, meaning that both energy waste and excessive emissions of pollution will fall.

3. Marketization level. This variable is found to have a different coefficient for different input slack variables namely an increase in the proportion of the non-stateowned economy conducive to a reduction in capital and energy input slack variables, whose coefficients are 0.3965 and -0.6650 , respectively. This arguably occurs because market-oriented reforms could reduce input waste and pollution emissions by strengthening corpo- 
rate governance and thus perfecting the incentive and restriction mechanisms of enterprises. However, as far as labor is concerned, due to the relative deprivation of capital and energy of non-state-owned enterprises, a certain degree of wasted labor is caused by capital scarcity.

4. Economic openness. The coefficients of an increase in the proportion of FDI to the three types of input slack variables are all significantly negative at $-0.2756,-0.1876$, and -0.0978 , suggesting that an increase of FDI reduces the three types of input and is conducive to local energy efficiency improvement. This is because China's continuous economic opening to the outside world is paving the way for the introduction of advanced technology, equipment, and management experience, thus improving local energy efficiency.

5. Energy factors. A higher proportion of raw coal consumption in total energy consumption is unfavorable for the capital, labor, and energy slack variables. Specifically, it may render more input waste, which explains the low energy efficiency of raw coal consuming provinces like Hebei and Shanxi. The energy endowment counts against a reduction in input slack variables, showing that the richer the energy resource of a region in China is, the higher the degree is of its energy waste. This is consistent with current regional trajectories of economic development in China. For example, Guangdong, Zhejiang, Jiangsu, Shanghai, and other developed provinces are net energy input regions and demand energy in large amounts from other provinces each year, while Inner Mongolia, Shanxi, Guizhou, and other provinces are large energy output provinces. In the latter provinces, the nature and degree of energy waste have given much cause for concern. An increase in energy prices is conducive to a reduction of various input slack variables, suggesting that such an increase encourages producers and operators to try to reduce energy input and thereby save on costs.

Due to the different influences of the environmental variables on various provinces, some provinces with a better operational environment manifest higher energy efficiency, while others with a poor operational environment present lower energy efficiency. Thus it is important to adjust the original input variable and apply the same operational environment to all the provinces in order to further investigate actual energy efficiency levels.

\section{Results Following an Adjustment of Input Variables In the Third Stage}

DEAP 2.1 software once again substitutes the adjusted input variables and original output variables into the formula to devise a solution. This process obtains energy efficiency after controlling for the influence of environmental factors and random errors. Table 3 shows these results.

First we employ the Wilcoxon sign rank test to analyze the significant difference in various efficiency values of the DEA model in the first and third stages. This analysis indicates that a significant difference exists between the first
Table 3. Energy efficiency estimation result in China (mean value between 2000-11).

\begin{tabular}{|c|c|c|c|}
\hline Region & $\mathrm{TE}$ & PTE & SE \\
\hline Beijing & 0.900 & 0.928 & 0.970 \\
\hline Tianjin & 0.892 & 0.925 & 0.964 \\
\hline Hebei & 0.856 & 0.873 & 0.981 \\
\hline Sanxi & 0.812 & 0.855 & 0.950 \\
\hline Inner Mongolia & 0.742 & 0.847 & 0.876 \\
\hline Liaoning & 0.929 & 0.953 & 0.975 \\
\hline Jilin & 0.824 & 0.869 & 0.948 \\
\hline Heilongiiang & 0.739 & 0.880 & 0.840 \\
\hline Shanghai & 1.000 & 1.000 & 1.000 \\
\hline Jiangsu & 0.904 & 0.929 & 0.973 \\
\hline Zhejiang & 0.956 & 0.956 & 1.000 \\
\hline Anhui & 0.787 & 0.824 & 0.955 \\
\hline Fujian & 0.982 & 0.987 & 0.995 \\
\hline Jiangxi & 0.793 & 0.844 & 0.940 \\
\hline Shandong & 0.846 & 0.929 & 0.911 \\
\hline Henan & 0.983 & 0.987 & 0.996 \\
\hline Hubei & 0.804 & 0.865 & 0.930 \\
\hline Hunan & 0.792 & 0.993 & 0.798 \\
\hline Guangdong & 1.000 & 1.000 & 1.000 \\
\hline Guangxi & 0.714 & 0.808 & 0.884 \\
\hline Hainan & 0.787 & 0.918 & 0.857 \\
\hline Chongqing & 0.806 & 0.855 & 0.943 \\
\hline Sichuan & 0.911 & 0.949 & 0.960 \\
\hline Guizhou & 0.783 & 0.838 & 0.935 \\
\hline Yunnan & 0.704 & 0.835 & 0.843 \\
\hline Shanxi & 0.726 & 0.837 & 0.867 \\
\hline Gansu & 0.805 & 0.929 & 0.867 \\
\hline Qinghai & 0.763 & 0.839 & 0.910 \\
\hline Ningxia & 0.964 & 0.987 & 0.977 \\
\hline Xinxiang & 0.774 & 0.859 & 0.901 \\
\hline Mean value & 0.843 & 0.898 & 0.929 \\
\hline
\end{tabular}

and the third stages in all the efficiency values, further suggesting that the environmental variables and random errors selected in the present paper do exert an influence over energy efficiency, making it necessary to adjust input variables. As seen from a comparison between Tables 1 and 3, after controlling for the influence of environmental factors and random errors, only two provinces are at the frontier of technical efficiency after adjustment: Guangdong and Shanghai. Compared with the first stage, Zhejiang, Fujian, 
and Henan retreat from the frontier of technical efficiency due to their decline in scale efficiency after controlling for the influence of environmental factors and random errors, suggesting that these provinces' previously high efficiency does not represent their true technical management level.

By comparing the energy efficiency values of various regions before and after controlling for the influence of environmental factors and random errors, pure technical efficiency is improved in most regions, but comprehensive technical efficiency fails to improve, mainly due to the decline of scale efficiency in these regions. The mean value of pure technical efficiency of all 30 provinces increases from 0.852 before adjustment to 0.898 after adjustment, while that of scale efficiency declines from 0.937 before adjustment to 0.929 after adjustment. This means that both environmental factors and random factors exert a significant influence over the energy efficiency of various regions.

The final measure highlights several features of energy efficiency in China. First, we observe a significant difference in the energy efficiency of different provinces. Shanghai, Guangdong, etc. have relatively higher energy efficiency, and their mean technical efficiency is at a relatively optimal level. These eastern coastal regions feature a high degree of economic openness and superior energy and technical conditions, which not only lay a solid basis for rapid economic growth, but also provide satisfactory technical support for energy conservation and emission reduction. In contrast, the central and western regions, including Yunnan and Guizhou, have lower energy efficiency and are facing serious energy waste and intensive environmental protection pressures, thus attaching great importance upon them for energy conservation and emission reduction policies.

Second, energy efficiency can be divided into pure technical efficiency and scale efficiency, and a comparison between the two can help investigate those factors that limit China's energy efficiency. During the period of investigation for the current study, pure technical efficiency is far lower than scale efficiency in terms of energy utilization in China, meaning that the factors limiting China's energy efficiency are mainly manifested through pure technical efficiency. As the scale efficiency of energy utilization in China has approached its optimal frontier, continued expansion of the energy input scale will cause limited efficiency improvements. Comparatively speaking, pure technical efficiency still has much space for improvement.

\section{Spatial Patterns and Features of Energy Efficiency}

In light of the changes in China's regional energy efficiency, as previously discussed, the key to the problem is how to employ a time sequence analysis to extract several typical spatial patterns of energy efficiency and thus provide a reference for energy efficiency improvement, energy conservation, and consumption reduction in China. With that in mind, and based on the matching relationship between energy efficiency and input level, this paper employs the Ward method to conduct cluster analysis, dividing the energy efficiency modes of various regions in China into four types. These types are described as follows:

\section{Mode Type I}

High efficiency and high input mode. These regions are represented by Jiangsu, Zhejiang, Tianjin, etc. As far as economic development level is concerned, these regions usually feature a rational matching degree of energy input level and relatively high energy utilization efficiency, but they also suffer from a relatively high degree of dependence upon foreign trade. In these regions the processing and manufacturing industry usually accounts for a relatively high proportion of all industries, meaning that enterprises tend to adopt a low-quality and low-price mode to participate in market competition and earn low processing profits. This influences not only the upgrading of the local product value chain, but also the improvement of energy efficiency. It is therefore necessary for these regions to accelerate research and development (R\&D) of their production processes and technology and conduct independent industrial innovation, in order to improve the quality and additional value of their products and to reduce the energy consumption of a unit's added value.

\section{Mode Type II}

High efficiency and low input mode. These regions are represented by Qinghai, Ningxia, etc. The pillar industries of these regions are tourism, agriculture, and animal husbandry. The proportion of secondary industries featuring high-energy consumption and high pollution is relatively low, and so these regions' pollution emissions tend to be relatively low, meaning they achieve relatively high energy efficiency. However, these regions still face certain problems, including a small enterprise scale and weak industrial competitiveness; the former influences independent innovative $\mathrm{R} \& \mathrm{D}$ and also directly limits the improvement of energy utilization efficiency. Thus, for the purpose of increasing industrial scale, it is necessary to limit smallscale projects and enterprises in the high-energy consumption industry, on the one hand, and promote enterprise reorganization on the other. Doing so will help to realize resource sharing inside the industry and improve these regions' overall economic strengths.

\section{Mode Type III}

Low efficiency and high input mode. These regions are represented by Hubei, Henan, etc. and usually feature relatively high input level and low energy utilization efficiency. Deeply influenced by the traditional planned economy, their industrial structure tends to be irrational, heavy industry-oriented, and energy-consuming, which in turn influences their energy efficiency. It is imperative for these regions to accelerate the upgrading of their industrial structure and develop new materials, energy, information technology, biological medicine, and other hi-tech industries that feature low environmental pollution and energy consumption. 


\section{Mode Type IV}

Low efficiency and low input mode. These regions are represented by Shanxi, Guizhou, etc., and usually suffer from widespread serious energy waste and environmental pollution caused by an excessive energy consumption structure. Thus, on the one hand these regions would benefit from actively researching new energy development technologies and accelerating the development of solar energy, nuclear energy, and other energies to achieve sustainable development. On the other hand, these regions could also benefit from enhanced regional investment appeal and expanded production scale through the development of their featured industries, so as to improve the scale effect and comprehensive efficiency of energy consumption.

\section{Convergence of Energy Efficiency}

This study thus far has highlighted the significant differences that exist between various regions in China in terms of energy efficiency. This section now presents a convergence analysis on the country's energy efficiency based on this differentiation, which helps not only to accurately grasp the changing trends of energy efficiency in certain regions, but also to clearly define the convergence features of energy efficiency and the development of overall energy conservation and emission reduction in China, thereby providing a sound basis for the establishment of regional environmental policies.

This paper employs an absolute convergence model to conduct a convergence tendency test as follows:

$$
\frac{1}{T-t}\left(\operatorname{LnTE}_{i, T}-\operatorname{LnTE}_{i, t}\right)=\alpha+\beta \operatorname{LnTE} E_{i, t}+\mu_{i, t}
$$

...where, $T E_{i, t}$ and $T e_{i, T}$ respectively represent initial and final energy efficiency values, $\alpha_{i}$ represents a constant term, and $\mu_{i, t}$ represents a random error term. If the value of $\beta$ is negative and can pass the significance test, then this suggests that there is absolute $\beta$ convergence. For the purposes of this paper, absolute convergence means that the energy efficiency growth speed of those regions with low initial energy efficiency tends to be higher than that of those regions with high initial energy efficiency.

The results in Table 4 indicate that between 2000 and 2012 the comprehensive technical efficiency of energy both in east China and nationwide manifests a divergence tendency, while that in west China presents a convergence state. However, the latter is statistically insignificant, to the point of not exceeding the efficiency values of central and east China. The results relating to comprehensive technical efficiency show a significant absolute convergence only in central China, suggesting that various provinces in central China tend to develop at the same steady state in terms of energy technical efficiency. The annual convergence rate of central China reaches $3.23 \%$. However, with the passage of time, the rise of its efficiency value fails to bridge regional gaps in comprehensive technical energy efficiency. Indeed,

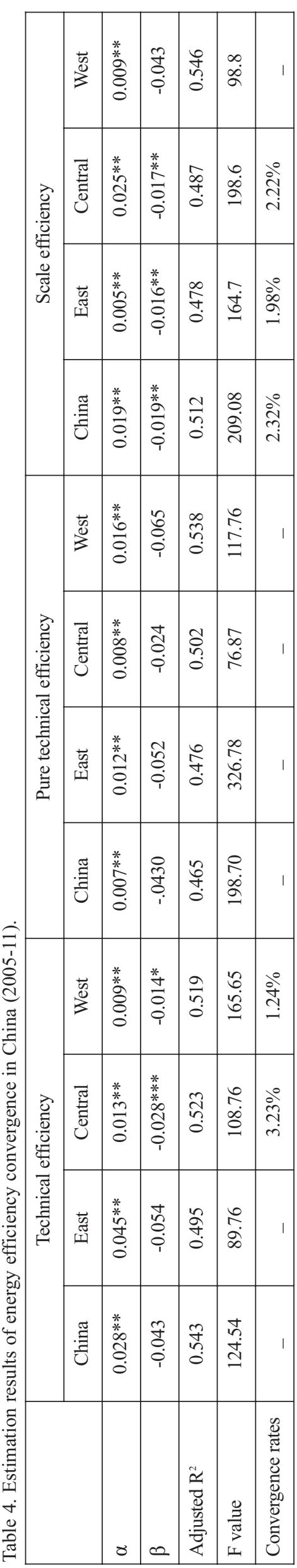


the gap between different regions' energy performance across China is widening.

With regard to all of China, or eastern, central or western China, pure technical energy efficiency presents no convergence. The scale efficiency for the whole country and in eastern and central China manifests a significant absolute convergence feature, with annual convergence rates, respectively, of $2.32 \%, 1.98 \%$, and $2.22 \%$. Conversely, western China presents no obvious convergence tendency, thus weakening to a certain extent the overall convergence level of China's total scale efficiency of energy. Based on this analysis, the interregional energy efficiency differences in China will remain at a relatively high level in the short term.

\section{Conclusions}

The current study has used the three-stage DEA model to measure the energy efficiency of 30 provinces in China between 2000 and 2012, and tested whether convergence exists in China's energy efficiency. The results indicate that: (1) In the second stage, the paper uses the SFA method, which excludes the influences of environmental factors and random errors to measure energy efficiency and find the efficiency values changed greatly, indicating that China's energy efficiency level is indeed influenced by external environmental variables such as industrial structure, marketization level, government intervention, etc. The application of the three-stage DEA model in the field of evaluating energy efficiency is reasonable and necessary.

(2) The energy efficiency values indicate firstly that there are significant regional differences in energy efficiency in China. Energy efficiency in eastern regions is higher than midwestern regions, which indicates that the developed economy, science and technology, and human resources in eastern regions greatly promote the improvement of efficiency, while efficiency in midwestern regions is lower than other regions due to highenergy consuming industries such as the pillar industry. Secondly, pure technical efficiency is far lower than scale efficiency in terms of energy utilization in China and is the primary cause constraining China's energy efficiency. In other words, pure technical efficiency has great space for improvement. Thirdly, based on the matching relationship between energy efficiency and input level, the country's energy efficiency can be classified according to four modes or characteristics: high efficiency and high input mode, high efficiency and low input mode, low efficiency and high input mode, and low efficiency and low input mode.

(3) The study also finds that, according to the convergence test of China's energy efficiency, energy comprehensive technical efficiency presents divergent trends, thus widening the difference in energy efficiency. The difference in regional energy efficiency should maintain a relatively high level in the short term.

By considering the numerous differences among various regions in terms of energy endowment, industrial structure, economic systems, and so forth, one may argue that differentiated energy strategies should be adopted in eastern, central, and western China. The eastern region suffers from a relatively high degree of dependence upon foreign trade. In addition, local enterprises are at the disadvantageous position in the global industry value chain, and the products have low added value, high energy consumption. Therefore the east should reduce its rigid dependence on external energy, transform the traditional industrial structure away from high-energy consumption, actively expand the import and export trades, strive for high-quality imported energy, break the bonds of traditional comparative advantage, enhance the ability of independent R\&D and innovation by importing and digesting advanced technology from foreign countries, and develop high-added value, low-power high-tech industries. And form a new dynamic comparative advantage by imbedding in a global production network. The industry structure in central regions tends to be "heavy," energyintensive industrial structure has seriously affected the improvement of energy efficiency. Therefore, the central region should receive the transfer of clear industry from eastern regions; improve energy efficiency in energy-intensive industries by updating equipment, adopting advanced technology and process, and strengthening energy management; fully tap the energy savings potential of high-energy consumption sectors; and accelerate the transfer of intensive growth. The phenomenon of energy waste and environmental pollution is widespread in western regions because of the irrational energy consumption structure. Therefore, for the west, local resources should be fully utilized to energetically promote the ecological tourism industry and cleaner production industry, and actively develop border trade and introduce ecological industrial projects with high economic benefits, thus achieving more sustainable economic development in this region. Furthermore, different regions should improve regional investment attractiveness by develop special industries, expanding product scale, and enhancing energy scale efficiency and comprehensive efficiency by dislocating the competition.

In the end, China should make full use of the convergence mechanism of energy efficiency and strengthen domestic energy cooperation to achieve coordinated development of regional energy economy. First, to improve the overall energy efficiency of China the steady improvement of energy efficiency in eastern regions should first be guaranteed and drive energy efficiency increase through spillover effects. Second, promote the efficient flow of capital, technology, and talent in China, strengthening the communication and cooperation between regions. The government should formulate relevant supporting policies tilted to Midwestern China, breaking barriers to improve energy efficiency. Thus promoting a more balanced and robust energy efficiency improvement. Third, strengthen international cooperation in energy technology, learn advanced technology and management experience from abroad. While China should also introduce energy-saving technologies which have been proved effective overseas, and upgrade, improve the existing energy-saving technologies continuously in this process. 


\section{References}

1. ANG B.W. Monitoring changes in economy-wide energy efficiency: from energy-GDP ratio to composite efficiency index. Energy Policy. 34, (2), 547, 2006.

2. GAO Z.Y., WANG Y. Classification of China provinces according to energy productivity and analysis for the differences. The Journal of Quantitative \& Technical Economics. 9, 46, 2006.

3. HU J L., WANG S.C. Total-factor energy efficiency of regions in China. Energy Policy. 34, (17), 3206, 2006.

4. HU J.L., KAO C.H. Efficient energy-saving targets for APEC economies. Energy Policy. 35, (1), 373, 2007.

5. MUKHERJEE K. Energy use efficiency in the Indian manufacturing sector : An interstate analysis. Energy Policy. 36, (2), 662, 2008

6. HONMA S., HU J.L. Total-factor Energy Efficiency of Regions in Japan. Energy Policy. 36, (2), 821, 2008.

7. CHEN T.Y., LAI P.Y. A comparative study of energy utilization efficiency between Taiwan and China. Energy Policy. 38, (5), 2386, 2010.

8. CHUNG Y.H., FARE R., GROSSKOPF S. Productivity and undesirable outputs: A directional distance function approach. Journal of Environmental Management. 51, 229, 1997.

9. MACPHERSON A.J., PRINCIPE P.P., SMITH E. R. A directional distance function approach to regional environmental- economic assessments. Ecological Economics., 69, (10), 1918, 2010.

10. POVEDA A.C. Economic development and growth in colombia: An Empirical analysis with super-efficiency DEA and panel data. Socio-Economic Planning Sciences. 45, (4), 154, 2011.

11. KIM K., KIM Y. International comparison of industrial $\mathrm{CO}_{2}$ emission trends and the energy efficiency paradox utilizing production based decomposition. Energy Economics. 34, (5), 1724, 2012
12. STERN D.I. Modeling international trends in energy efficiency. Energy Economics. 34, (6), 2200, 2012.

13. BERTHOLT A., PAN J.N. Evolving the latent variable model as An environmental DEA technology. Omega. 41, (2), 315, 2013.

14. LU C. C., CHIU Y.-H., SHYU M.-K., LEE J.-H. Measuring $\mathrm{CO}_{2}$ emission efficiency in OECD courtiers: Application of the Hybrid Efficiency model. Economic Modeling, 32, 130, 2013.

15. NOAILLY J. Improving the energy efficiency of buildings: The impact of environmental policy on technological innovation. Energy Economics. 34, (3), 795, 2012.

16. BALEZENTIS A., BALEZENTIS T., STREIMIKIENE D. The Energy Intensity in Lithuania during 1995-2009: A LMDI Approach. Energy Policy. 48, (1), 7322, 2011.

17. HERRERIAS M.J. World energy intensity convergence revisited: A weighted distribution dynamics approach. Energy Policy. 49, (10), 383, 2012.

18. MENG M., PAYNE J., LEE J. Convergence in per capita energy use among OECD countries. Energy Economics. 36, (3), 536, 2013.

19. STERN D.I. Modeling international trends in energy efficiency. Energy Economics. 34, (6), 2200, 2012.

20. FRIED L. Accounting for environmental effects and statistical noise in data envelopment analysis. Journal of Productivity Analysis. 33, (17), 157, 2002.

21. SHANG J.K., HUANG W.T., LO C.F,WANG F.C. Ecommerce and hotel performance: three-stage DEA analysis. The Service Industries Journal. 28, 529, 2008.

22. SHYU J., CHIANG T. Measuring the true managerial efficiency of bank branches in Taiwan: A three-stage DEA analysis. Expert Systems with Applications. 39, 147, 2012.

23. CHARNESS A., COOPER W.W.,RHODES E. Measuring the efficiency of decision units. European Journal of Operational Research. 94, (2), 95, 1978.

24. SHI F., SHEN K.R. The Total Factors Energy Efficiency under the Condition of Market Segmentations. World Economy. 9, 49, 2008. 
